\title{
A clínica da psicose: um estudo de caso
}

The clinic of psychosis: a case study

La clínica de la psicosis: un estudio de caso

Recebido:10/07/2020

Aprovado: 21/01/2021

Publicado: 18/04/2021

\author{
Silvia Herszkowicz ${ }^{1}$ \\ Araceli Albino ${ }^{2}$
}

Este é um estudo de caso realizado em 2018, com o objetivo de descrever a proposta de atendimento de uma paciente com estrutura psíquica psicótica. 0 casoé oriundo da proposta de atenção psicanalítica em uma clínica social, no modo individual e grupal, por um período superior a oito anos. Os encontros grupais e as sessões individuais ocorriam semanalmente. No modo grupal, com a participação de quatro analistas, havia além uma tríade social: pacientes, mamãe e papai. No modo individual, a relação se dava analista-analisando. De um começo pouco participativo no grupo e nas sessões individuais, a paciente (Rebeca - nome fictício), evoluiu melhorando sua sociabilização, sua relação familiar, e até mesmo as questões profissionais.A clínica da psicose é uma árdua tarefa, mas Rebeca conseguiu se posicionar e se descolar da família. Atualmente, está trabalhando, tem mantido um bom contato social com os demais membros do grupo terapêutico (Grupo Vida) e com seus colegas de trabalho. Essa clínica é cativante porque, de alguma forma, o vínculo com os pacientes permanece; é uma análise interminável, que exige coragem e determinação do analista.Aponta-se a importância da viabilidade da clínica da psicose, na proposta psicanalítica, via transferência ativa.

Descritores: Psicanálise; Transtornos psicóticos; Terapêutica.

This is a case study carried out in 2018. It aims to describe the proposal for the care of a patient with a psychotic psychic structure. The case comes from the proposal of psychoanalytic care in a social clinic, in the individual and group mode, for a period of more than eight years. Group meetings and individual sessions took place weekly. In group mode, with the participation of four analysts, there was also a social triad: patients, mom and dad. In the individual mode, the relationship took place as an analyst-analyzed. From a little participatory beginning in the group and in the individual sessions, the patient (Rebeca fictitious name), evolved improving her socialization, her family relationship, and even her professional issues. The psychosis clinic is an arduous task, but Rebeca managed to position herself and detach herself from the family. Currently, she is working, has maintained good social contact with the other members of the therapeutic group (Grupo Vida) and with her co-workers. This clinic is captivating because, in some way, the bond with patients remains; it is an endless analysis, which requires courage and determination from the analyst. The importance of the viability of the psychosis clinic is pointed out, in the psychoanalytic proposal, via active transference.

Descriptors: Psychoanalysis; Psychotic disorders; Therapeutics.

Este es un estudio de caso realizado en 2018, con el objetivo de describir la propuesta de atención a una paciente con estructura psíquica psicótica. El caso proviene de la propuesta de atención psicoanalítica en una clínica social, en la modalidad individual y grupal, por un período de más de ocho años. Las reuniones de grupo y las sesiones individuales se celebraron semanalmente. En la modalidad de grupo, con la participación de cuatro analistas, había además una tríada social: pacientes, mamá y papá. En la modalidad individual, la relación era la de analista-analizado. Desde un inicio con poca participación en las sesiones grupales e individuales, la paciente (Rebeca - nombre ficticio), evolucionó mejorando su socialización, su relación familiar e incluso cuestiones profesionales. La clínica de psicosis es una tarea ardua, pero Rebeca logró posicionarse y desprenderse de la familia. Actualmente, está trabajando, ha mantenido un buen contacto social con los demás miembros del grupo terapéutico (Grupo Vida) y con sus compañeros de trabajo. Esta clínica es cautivadora porque, de alguna manera, el vínculo con los pacientes permanece; es un análisis interminable, que requiere valor y determinación por parte del analista. Se señala la importancia de la viabilidad de la clínica de la psicosis, en la propuesta psicoanalítica, vía transferencia activa.

Descriptores: Psicoanálisis; Trastornos psicóticos; Terapéutica.

1. Administradora de Empresas. Psicanalista. Especialista em Psicanálise. ORCID: 0000-0002-9705-7075E-mail: psicanalista.silvia@gmail.com 2. Psicóloga. Psicanalista. Doutora em Psicologia. Coordenadora Técnica e Professora do Núcleo Brasileiro de Pesquisas Psicanalíticas, São Paulo, SP, Brasil. ORCID: 0000-0002-1391-8553 E-mail: araceli.albino@uol.com.br 


\section{INTRODUÇÃO}

A

psicanáliseé contra a generalização de causa e efeito. Na psicose, o sujeito faz uma ruptura com a realidade psíquica, "um buraco, uma falha, um ponto de ruptura com a estrutura do mundo exterior, que se acha preenchido pela peça trazida pela fantasia psicótica"1.

Na perspectiva freudiana de início se contraindicou o trabalho com a clínica da psicose, ao mesmo tempo que se abre essa possibilidade, em ressalvas que seja necessário pensar modificações no método psicanalítico, para que esse tratamento se torne possível: "As psicoses (...) são impróprias para psicanálise, ao menos tal como tem sido praticada até o momento"2.

A dificuldade encontrada não se situava exatamente do lado do psicótico, mas ao lado do analista na transferência. Pontuando-se que o aforismo do delírio é a tentativa de cura ou de solução na psicose, ou seja, há um movimento do psicótico em direção à estabilização. Entretanto, a especificidade da transferência nessas "neuroses narcísicas" inviabilizaria seu tratamento analítico ${ }^{3}$.

$\mathrm{Na}$ psicose, não há simbolização, o sujeito vivencia a coisa. 0 psicótico interpreta literalmente o que pensa, o pensamento é vivido ipsis litteris, não há representação. Ele vive o que é. As palavras são reais. "O delírio tem função de reconstrução, o que tomamos como doença na verdade é uma tentativa de cura" 3 .

0 mecanismo específico da psicose seria a rejeição (Verwerfung). E o que caracteriza a diferença entre neurose e psicose é que na primeira existe um conflito entre o $E u$ e o $I d$, enquanto na segunda as dificuldades estão na relação entre o eu e o mundo externo ${ }^{4-6}$. Tanto na neurose como na psicose há uma perda na relação que o sujeito estabelece entre o eu e a realidade ${ }^{6}$. Esse afastamento da realidade se caracteriza:

$\mathrm{Na}$ neurose, o eu através do recalque, suprime a pulsão oriunda do isso. Na contrapartida do neurótico, que restringe apenas uma parcela da realidade, na psicose ocorre a rejeição radical desta que caracteriza sua estruturação patológica. Por conta da fuga do eu na relação com o mundo externo, há a predominância do isso ou, emoutras palavras, do inconsciente, em suas manifestações 4 .

A libido tem dois destinos, uma parte fica no próprio eu e a outra e investida em objetos externos (cuidadora), no entanto a psicose fica retida só no eu. Não há investimento em objeto externo, de modo que o estabelecimento da transferência na psicose é de outra ordem, exige um outro manejo ${ }^{6}$.

Não se trata de recusar a transferência na psicose, mas isto é diferente da neurose de transferência. A proposta freudiana não avança muito nesse tema, mas é trazida no olhar lacaniano, que aponta que o que se estabelece entre o analista e o paciente psicótico, é que o analista sempre ficará na posição especular imaginária. 0 psicótico sobrepõe sujeito e objeto, e fala como sujeito humano da sua posição de objeto7.

Segundo Lacan1, "as psicoses são, se quiserem - não há razão para se dar ao luxo de recusar empregar esse termo -, o que corresponde àquilo a que sempre se chamou, e a que legitimamente continua se chamando, as loucuras".

A psicose na direção lacaniana é uma estrutura diferente da neurose. Há na psicose um mecanismo de defesa denominadoforaclusão.A palavra foraclusão vem do campo jurídico e significa a privação de uma faculdade ou de um direito que, por não terem sido executados no tempo devido, se tornaram obsoletos ${ }^{7}$. Porém, antes de ficarem restritas ao uso jurídico, estas expressões no francês significavam "excluir, privar, expulsar, impedir, banir, omitir, cortar" e até mesmo "prender do lado de fora, fechar no exterior, jogar fora, rejeitar". Foracluído é aquilo que saiu de cena, que não está simbolizado, que não tem sentido7.

Mas tanto a direção freudiana, quanto lacaniana incita o analista a ouvir o que os psicóticos têm a dizer sobre si e sobre seu adoecimento. Essa escuta do discurso psicótico propõe afluir uma possibilidade de tratamento, ou melhor, uma clínica da psicose.0 sujeito da 
psicose, mesmo com sua fala às vezes desconexa, traz consigo um universo, com conteúdos que também merecem ser ouvidos.

0 conceito de transferência é fundamental para a psicanálise, sobretudo em um trabalho que pretende investigar os aspectos do tratamentoda psicose e, como em qualquer prática analítica, o trabalho acontece a partir do sujeito.

A libido tem dois destinos: uma parte fica no próprio eu e a outra é investida em objetos externos (cuidadora) ${ }^{8}$. 0 psicótico se endereça ao analista como aquele que está no lugar do que escuta. Não importa o que ele fala, mas sabe que tem alguém a lhe escutar. A partir dessa escuta, o analista vai dando um sentido não lógico do que é dito, mas um sentido de importância do dito pelo paciente. Na neurose, o paciente coloca seu analista no lugar do sujeito suposto saber e na psicose, o paciente fala para o analista o que ele sabe de si.

Na psicose, o analista é uma testemunha da posição que seu paciente psicótico ocupa no mundo. 0 analista do psicótico não pode extrapolar sua condição somente de quem escuta, não prescreve condutas, mas aponta caminhos. Quem direciona o tratamento é o psicótico, pois ele próprio vai interpretando os seus sintomas a partir de seus delírios. E, o analista escuta, possibilidadeesta de que o psicótico tenha um lugar.

A transferência é uma troca, o paciente se dá e o analista devolve. Esse é um acontecimento de amor, no sentido lacaniano: "Amar é dar o que não se tem a alguém que não o quer"9. A transferência só é possível quando o analista respeita a singularidade de cada paciente.É o desejo do analista que lhe permitirá respeitar essa singularidade. Se não há interpretação nessa clínica, há o desejo do analista.

Na clínica da psicose o analista trabalha muito mais com a produção dos delírios que advém do inconsciente que está aberto. 0 delírio é uma tentativa de reestabelecimento, um processo de reconstrução ${ }^{10}$.

"O psicanalista não deve recuar diante da psicose", não se apresenta como o sentido heroico de sustentar esse fardo, mas sim no intuito de produzir, por um lado, um saber que ajude a resolver os problemas que a psicose impõe à psicanálise e, por outro, diminuir os obstáculos que ela apresenta por meio da transferência ${ }^{11}$.

Surtos, delírios e alucinações são defesas para lidar com a invasão do grande outro. 0 analista oferece um espaço de escuta para esses delírios e alucinações,interpretando literalmente o que o paciente conta.

A primeira atitude do analista é buscar compreender a estrutura clínica do paciente, isso permitirá ao analista não só pensar as coordenadas do tratamento, bem como observar que lugar ele ocupa nessa relação12.

Obviamente, o analista não se restringirá a descrições nosográficas, porque isso nada fala do sujeito em questão, mas ter um diagnóstico estrutural poderá auxiliar na compreensão do sujeito, a partir da escuta de suas singularidades.

0 analista deve ocupar a posição de "secretário doalienado",permitindo a criação de um vínculo, para que surja daí a possibilidade de se trabalhar com o sujeito ${ }^{13}$.

Desde os primórdios da criação da psicanálise como campo de saber, ainda que de forma incipiente, a transferência aparece como plano decisivo em que se dão os caminhos de uma análise, ou seja, o que se sabe da análise é seu início e seu término. 0 meio do caminho é permeado pela transferência.

O campo transferencial pode ser entendido como um plano de compartilhamento afetivo por meio do encontro lúdico, que favorece a produção de sentidos para as experiências de cada um dos parceiros da análise ${ }^{14}$.

Na relação analítica e possibilidade grupal,a transferência ativa na clínica das psicoses, o "norte"é a qualidade do encontro afetivo entre analistas e analisandos. Na atividade em grupo os analistas são catalizadores de afetos, enquanto um ocupa o lugar da figura paterna, outro ocupa o lugar da figura materna, oscilando entre esses dois lugares os afetos circulam ${ }^{11}$. 
Os analistas devem oferecer ao paciente a possibilidade de vivenciar, experimentar a vida, a relação que se estabelece entre paciente e analista é que o analista não se restringe a falar do paciente, mas ele ouve e fala com o paciente ${ }^{15}$.

$\mathrm{O}$ analista promove um pacto através da fala, um pacto que simboliza suas ausências, presenças e os limites de suas ações e comportamentos. Dessa forma o analista atrai para si as partes fragmentadas do inconsciente psicótico, bordeando essas partes de afeto amoroso e de significação. Essa força gradativamente vai atraindo ao seu entorno outros objetos, dando-lhes outros significados suportáveis ${ }^{11}$ :

A transferência ativa é uma voz que se inclui, que fala, faz furo, deixa uma marca e tem um nome (psicanalista, psiquiatra, remédio, grupo, família, sim, não e outros.) que o paciente convoca. É uma convocação amorosa. É a relação estabelecida entre o analista e o paciente de estrutura psicótica sob a égide do puro desejo que redireciona os fragmentos libidinais do psicótico. Ela abre caminho para a interpretação ativa, que é direta e inquestionável, oferece amor, e impõe limites. A ação interpretativa auxilia o psicótico a compreender seu universo imaginário e diferenciá-lo do mundo real, permitindo que permaneça maior parte do tempo em realidade, longe de delírios e alucinações ${ }^{11}$.

Defende-se aqui, que a clínica de psicoses pela psicanálise é possível e que a transferência de dá de um modo diferente das neuroses. Assim, este artigo tem como objetivo descrevera proposta de atendimentode uma paciente com estrutura psíquica psicótica.

\section{MÉTODO}

O presente trabalho foi realizado numa clínica social de um centro de pesquisas em psicanálise, em 2018. A pessoa descrita neste estudo de caso foi selecionada pelas características do seu caso clínico.

As sessões individuais ocorriam semanalmente (por mais de oito anos), e ela também participava de um uma análise de grupo na própria clínica. Alguns dados biográficos que pudessem permitir o reconhecimento da real identidade, foram omitidos e/ou alterados neste relato para a preservação do anonimato dela.

Nas citações diretas das transcrições de diálogos nas sessões terapêuticas, o nome real foi substituído por um nome fictício, no caso Rebeca. A fonte de informação clinicamente relevante foi o diário de sessões, no qual foram transcritos os encontros terapêuticos.

Para esse estudo, foi utilizada a metodologia do estudo de caso, o que implica uma efetiva participação do analista, em primeiro lugar como sujeito de investigação.

\section{RESULTADOS}

Rebeca tem 44 anos, solteira, pertence a uma família de seis irmãos. 0 pai é de origem árabe, portanto, oriundo de uma cultura severa, com regras morais muito rígidas; a mãe é húngara e, (de acordo com Rebeca), tornou-se prisioneira de um campo de concentração aos 14 anos e, tem transtornos psiquiátricos desde quando Rebeca tinha 3 anos. A partir dessa data, foi internada com diagnóstico de esquizofrenia em uma instituição nas cercanias de São Paulo. Pouco tempo depois, o pai se casou com a secretária, com quem teve uma filha, e esta segunda esposa também apresenta transtornos psiquiátricos severos.

Rebeca foi indicada por uma participante do Grupo Vida, em 2011. Nas reuniões, estava sempre muito assustada, introspectiva, os olhos muito arregalados, e quase não falava. Seu desespero interno era tão intenso que transbordava. Tentava se certificar de que o ambiente era seguro. Qualquer movimento era seguido pelo seu olhar assustado. Ficou várias reuniões quieta, não participava, não falava, nem quando requisitada respondia às perguntas. Havia também um total abandono do ponto de vista da higiene pessoal e de cuidados mínimos consigo mesma. 
Quando começou a frequentar o Grupo Vida, estava usando muitos medicamentos, era acompanhada por uma psiquiatra há mais ou menos vinte anos, e fazia uso de Carbolitium e antidepressivo de última geração. No entanto, seu discurso era desarticulado e muito confuso; em algumas sessões, somente construía frases desconexas. Muito sonolenta, com odor fétido, trêmula e com muita fome.

Muitas vezes, não cuidava do corpo, apresentava comportamentos repetitivos de friccionar uma mão na outra e, em seguida, tocava articulações como joelhos, tornozelos e cotovelos. Até que, um dia, me procurou para atendê-la individualmente, porque outra paciente do grupo relatara uma sensível melhora com sessões individuais. Aceitei atendê-la. No início, foi muito difícil para as duas. Ela temia confiar em mim, e eu, por minha vez, nunca tinha atendido a um caso de psicose individualmente.

Nas reuniões do Grupo Vida, ela tentava esconder que tinha problemas, não queria que ninguém soubesse de suas dificuldades, embora estas estivessem presentes, inscritas em seu corpo: mãos trêmulas, fala desconexa, irritabilidade constante, alto nível de agressividade. Havia também um sentimento persecutório - que ela sempre relatava nas sessões individuais - em relação a uma das terapeutas do grupo.

Com o transcorrer do atendimento individual, Rebeca conseguiu realizar conexão entre o sentimento persecutório em relação à referida terapeuta e a figura de sua mãe, quanto à austeridade e à distância. Nas sessões, afirmava: a terapeuta é distante de mim como minha mãe. É próxima e, ao mesmo tempo, distante.

No primeiro ano de atendimento individual, contava sua história totalmente estratificada. Era difícil entender e separar o que pertencia à sua infância do que era atual. Nos momentos em que se referia a um namorado, havia uma mistura entre realidade e fantasia.

No segundo ano de atendimento individual, foi se tornando mais confiante e mais tranquila, evidenciando constância na terapia de grupo, usando os medicamentos e comparecendo ao atendimento individual. Concomitantemente ao atendimento individual, seguia frequentando o grupo. Na terapia grupal, começou a entender que podia se espelhar no grupo; observava os outros pacientes, notava quem havia melhorado e quem não estava bem e relatava essas observações durante os atendimentos individuais.

Embora todos fossem referência de espelhamento, ela sempre falava muito mal de todos os participantes; sempre havia algo a pontuar, mas com um olhar crítico, severo. Esse segundo ano foi de avanços. Sempre que solicitada, conseguia falar de suas experiências com mais clareza para o grupo. Nas sessões individuais, esboçava raiva contra toda a família, que não a aceitava como um ser humano livre e com vontade própria e continuava se sentindo perseguida pela terapeuta que coordenava o grupo.

Nas sessões individuais, apresentava-se muito mais agressiva. A analista se posicionava como depositária dessa raiva e, muitas vezes, ela se levantava ameaçando agredi-la fisicamente. Interpelando-a, a analista dizia-lhe que poderia fazer tudo no setting, menos tocar em mim, sob pena de não mais atendê-la.

$\mathrm{Na}$ análise individual, Rebeca começou a juntar pedaços de sua vida em blocos de assuntos que se relacionavam, e seu discurso era mais coerente. A analista entrava em seus delírios. Quando ela se acalmava, podia-se conversar a respeito, tentando chegar a uma compreensão possível.

Durante o processo de análise individual e participação no grupo, a paciente foi se fortalecendo, buscou desenvolver outras atividades sociais, frequentou cursos preparatórios para concursos públicos, cursos de estética e de massagem e foi aprendendo a enfrentar sua família, o que para ela, era uma batalha a ser vencida, uma vez que, a cada dia, a estrutura familiar colocava à prova sua sanidade mental.

Embora tenha sete irmãos, pai, madrasta e sobrinhos, Rebeca sente que não encontra apoio em familiar algum. O Grupo Vida ocupa o lugar dessa família e a análise individual contribuiu para que ela se aproprie desse espaço. 
Os participantes do grupo reconhecem sua melhora, seus esforços e suas conquistas. Parece que aos poucos, a paciente vai renunciando à luta por uma família ideal, suportando esta espécie de vazio, que deu lugar ao desejo de familiarizar-se no grupo. Atravessando o fantasma, foi, aos poucos, perseguindo desafios novos, escolhidos por ela mesma, como desejar construir uma família no grupo, que se sustenta no paradigma da família (pai, mãe e irmãos), na qual os afetos circulam livremente.

Nos últimos dois anos, o trabalho nas sessões individuais tem sido construir opções em que ela possa se interessar e ser útil, pois é seu desejo ter um trabalho e ser produtiva. Tem duas formações universitárias e sua maior aspiração é atuar na área da educação. Atualmente, tem noção do que pode e do que não pode fazer e está tentando lidar com suas limitações, sem os delírios de ser uma grande professora. Durante todo esse tempo, tentou vários relacionamentos afetivos, mas sem sucesso. Sonha com o casamento e com a oportunidade de morar bem longe de sua família, que ela considera a grande responsável por seu adoecimento.

Com a direção de tratamento baseada na transferência ativa, tanto no grupo quanto na sessão individual, o que se tem buscado é desmontar as fantasias impossíveis que ela tem, entrando e saindo do seu delírio quando necessário, buscando sentidos que lhe permitam diferenciar delírios e alucinações da realidade que a circunda.

Entende-se que esses delírios e alucinações são, talvez, o grito por socorro que Rebeca emite, buscando encontrar soluções para enfrentar a vida, o mundo e as pessoas. Em lugar de submeter-se ao capricho do olhar do Outro, exigente e perverso, a paciente minora o gozo, e tenta reestruturar a sua relação com os outros. Percebe que aceitar seus limites e conviver com perdas necessárias é o caminho para se haver com seus desejos de modo responsável.

Portanto, o outro deixa de ser tão persecutório, para se tornar parceiro, mas em outra dimensão, o que ela vem demonstrando na análise e na sua relação de afinidade com os participantes do grupo. 0 que se tenta, com essa transferência interminável e maciça, é dar-lhe suporte e certa segurança, para que consiga estar socialmente inserida no mundo.

$\mathrm{Na}$ análise, ousa-se cooperar para que ela perceba o entorno e suas possibilidades. 0 analista, quando suporta e deseja continuar nessa relação transferencial na clínica da psicose, deve estar ciente de que há um vínculo muito forte, constante e maciço, uma alta demanda, bem mais intensas que as de um paciente neurótico.

É possível observar sua melhor reintegração social, participando mais ativamente do grupo, e até solicitando mais atendimentos individuais, sempre em busca de alternativas que a deixem mais feliz.

Em uma das últimas sessões, Rebeca chega com um ar preocupado e se percebe que ela deseja dizer algo. Começa relatando que sua missão é salvar o diabo da morte, porque ele está amaldiçoado por Deus, e ela seria a única pessoa que poderia ajudá-lo. Reforça essa ideia dizendo:

O diabo me matando, teria a vida eterna, é o que ele pensa. Ele me matando ele tira a única esperança de vida que ele tem. Mesmo porque ele me mata e depois morre para sempre, porque o que se faz para o outro volta para você, $e$ quem vive sou eu. Deus me deu a missão de matar o diabo.

Quando termina a narrativa, pergunto-lhe: Há quanto tempo você tem esses pensamentos? Ela responde:

Fiquei doente porque não consegui cumprir essa missão, que Deus me preparou em sonho, eu tenho medo. Isso é o que mais me incomoda, mais do que tudo.

$\mathrm{Na}$ tentativa de entender seu delírio, lhe interrogo, dizendo: Rebeca, você acha realmente que Deus te daria uma missão tão complicada? o que te leva a pensar que você seria a escolhida para realizar essa tarefa que é tão difícil? Ao que ela fala:

Mas não penso isso, me vem em sonho, eu tenho medo.

Tentei uma abordagem: Proponho que façamos um pacto com Deus, para que ele a libere dessa missão.Tendo em vista que ela sempre relata que faz boas coisas, e que aquilo que se faz de bem ou de mal retorna, então, quem sabe Deus poderia livrá-la dessa missão tão difícil? 
Para o desenvolvimento de um projeto acerca de um livro sobre a trajetória do Grupo Vida, foi solicitado aos participantes que cada um contasse sua história de vida, a partir da sua visão. Rebeca gostou da ideia. Foram tomados cuidados necessários, tais como assinatura do Termo de Consentimento Livre e Esclarecido. Durante quatro sessões, relatou sua história. Foi um exercício difícil, ela revivia sua história a cada palavra, ia e voltava por caminhos tortuosos e desgastantes, era como se estivesse montando uma colcha de retalhos. Não havia um número predeterminado de sessões.

Pediu-se a ela que falasse sobre si. Coube-lhe escolher como construiria seu relato. As falas construídas por Rebeca nas sessões traziam um conteúdo muito perverso, ficando evidente que a paciente é e foi diuturnamente vítima de abuso psicológico, por parte de sua família adoecida. As falas foram transcritas e, após leitura, solicitou-se que ela dissesse como percebia sua própria história. Ao ouvir sua história, inicia comentando que:

Indo para o inferno a pessoa sofre muito.

Pela primeira vez, faz um discurso incluindo o outro e seus problemas:

Se você se focaliza no outro, aí você se anula, anula o seu problema, você não fica focalizado em você, fica focalizado no outro. Ai, eu estou doente, ai, eu não tenho namorado. Falando assim, você está fazendo um buraco no chão e se afundando dentro dele. Agora, quando você se focaliza em algo externo que não é seu, coloca o foco em outro lugar e não nos seus problemas, sua vida fica melhor. Porque os outros também têm problemas.

Depois de quase oito anos de tratamento, essa fala de Rebeca parece evidenciar que ela consegue ver que a analista a enxerga com possibilidades de interagir em sociedade, que vendo a si, ela consegue perceber o outro. Outro fato que corrobora esse pensamento é sua atividade profissional. Ela conta, feliz, que foi a melhor vendedora do mês e, com isso, ganhou prestígio e rosas vermelhas. Afirma que a equipe é muito boa, embora muitos falem mal, mas ela não toma mais para si essas agressões, e se tornou muito divertida.

\section{DISCUSSÃO}

A clínica psicanalítica ensina que os fenômenos psíquicos são comuns, e as variações se dão quantitativamente. Entre os humanos, não há diferenças substanciais, qualitativamente os humanos são semelhantes.

Considerando que em Rebeca se usou atividades grupais, o grupo em questão tem a permanência de analistas por um longo período, o que gerou estabilidade.

Observou-se, também, que a presença de mais dois analistas junto à coordenadora do grupo suscitou a constituição de laços duradouros e seguros entre pacientes e analistas. Com o passar do tempo, o grupo foi assumindo contornos de "família" e, a coordenadora foi adotando um papel da figura paterna, que interdita quando necessário. Já a outra analista colaboradora ocupou uma posição mais receptiva, carinhosa, a figura materna, e os demais psicanalistas se integravam ao grupo como irmãos.

Atualmente, percebem e comentam as presenças e ausências dos companheiros, comunicam-se extragrupo, trocando mensagens por Whatsapp, mobilizando-se, dessa forma, para ajudar uns aos outros em diferentes momentos.

No terceiro ano de atendimento a Rebeca, a transferência ativa já estava instaurada. Esse termo traz a ideia de que a presença do analista pode garantir ao psicótico o seu lugar de sujeito ${ }^{11}$.

Na transferência ativa, o analista se arvora como ponte, no sentido de que ele traz para o psicótico a ligação entre o real e o imaginário. E como se faz isso? Via afeto. O analista provoca a transferência ativa apresentando um objeto de afeto positivo para que o sujeito psicótico possa introjetar o objeto bom ${ }^{11}$.

Essa transferência se dá via linguagem, o analista vai montando junto com o psicótico um mosaico, as falhas e as fissuras não são tamponadas, mas, de certa forma, é possível ao psicótico remontar sua história. A transferência ativa é uma voz que se inclui, que fala, faz furo, deixa uma marca e tem nome (psicanalista, psiquiatra, remédio, grupo, família, sim, não e 
outros) e o paciente convoca quando suscita. É uma convocação que acontece, não por ordem do acaso, senão por algo que se pode denominar amor ${ }^{11}$.

Havia uma referência de Rebeca a sua família, oriunda de suas experiências no Grupo Vida. Este grupo é uma tentativa de escapar das formas tradicionais que são oferecidas ao paciente psicótico, pois oferece a possibilidade desse paciente ter um lugar no mundo.

Por um lado, busca-se a estabilização do paciente; por outro, a ampliação da possibilidade de criação de laços sociais, via transferência ativa. A palavra ativa do analista permite ao paciente psicótico ter uma verdade para sustentar sua existência, o acting de amor que permite acreditar numa verdade: que o analista é capaz de ajudá-lo a viver. Esse imaginário passa a ser um polo atrator e organizador das pulsões fragmentadas do psicótico. A imagem do analista será introjetada como sendo a única figura capaz de fazê-lo viver ${ }^{11}$.

o curso de uma análise pode ser definido como o espaço e o tempo do manejo da transferência; isto é, o processo psicanalítico está intimamente relacionado às variabilidades da afetividade que circula entre analista e analisando ${ }^{16} .0$ analista se dispõe a ser usado como um "João teimoso", e se oferece como suporte das mais intensas manifestações afetivas previstas pela transferência, será recompensado com a superação de muitas das "resistências objetivas", impostas pelo tratamento padrão. Assim, a "inovação" é resgatar da regra fundamental a dimensão de liberdade, perdida em grande parte ao longo do processo de institucionalização da psicanálise ${ }^{16}$.

Não se trata de inovar a clínica, já que Lacan, como muitos outros psicanalistas, já vinha inventando, há muitos anos, o manejo com o paciente religioso ${ }^{16}$. Como exemplo, é interessante citar o marcante encontro de Lacan com Marie de La Trinité, em que a paciente, uma freira católica, procurava ajuda para se tratar, após um período de intenso sofrimento.

Sem levar em conta os detalhes do caso, Marie de La Trinité, no período em que busca tratamento, passa pela competência de diversos médicos, dentre os quais Lacan se destaca, segundo ela, por uma habilidade diferenciada em compreender as coisas espirituais. Sobre a experiência com Lacan, afirma:

Não há nada demais a dizer sobre o tratamento em si; a não ser que, ao invés de me confinar em Freud como os médicos precedentes, ele percorre continuamente ao longo das sessões todas as escalas da natureza humana [...]. Me sinto muito segura com ele, pois ele compreende as coisas espirituais, não as elimina como os médicos precedentes, ao contrário ${ }^{16}$.

Esta abordagem permite dizer que "as coisas espirituais" que Rebeca abordou, se bem escutadas pelo analista, podem se tornar uma via de retificação da narrativa do sonho que ela traz ao analista. Em vez de matar o diabo, a paciente aceita celebrar um novo pacto com o Deus que pode ser exigente, mas também pode negociar, colaborar, aceitar novas propostas e possibilidades. 0 analista assume o manejo do delírio, posicionando-se como o outro que escuta, e não como o outro que exige.

Escutando, embora não responda ou aconselhe Rebeca, o analista pensa alto, e é notado por ela como o outro da relação, que oferece suporte, algo diferente do que ela experimentou no passado, delirando, na relação com a família, com os médicos, com o Grupo Vida.

Portanto, a realização do pacto com Deus tornou-se experiência nova, originando nova abordagem dos desafios com que Rebeca teve e terá de se defrontar pelo resto da vida, com o outro da realidade, com os diversos parceiros no trabalho, na vida amorosa, na religião e outros. Ela tem que acabar com o mal, mas, ao exterminá-lo, ela se torna o mal e só conseguirá ficar bem se fizer outro pacto. A aceitação desse pacto a tranquiliza.

Nesse momento, se percebe que seu semblante fica mais leve, ela parece aliviada, sobretudo, quando se diz que o delírio é um caminho que ela encontra para fugir de sua própria história e, ao mesmo tempo, dar conta de vivê-la.

É contra essa dor que Rebeca luta. Diz que está aliviada por ter contado e que o que a analista falou tirou-lhe um grande peso, tendo em vista que não seria mais necessário realizar 
tal feito. As manifestações psicóticas, como o delírio ou a alucinação, não são efeitos imediatos de uma dada causa, mas consequências derivadas da luta travada pelo $E u$, para se defender de uma dor insuportável ${ }^{18}$.

Em outra sessão, Rebeca delira que é um anjo e pode proteger Axl (vocalista da banda Guns N' Roses) mesmo à distância, comparando-se a ele. A possibilidade de ajudar Axl, de certa forma, a ajuda também. Não se faz nenhuma intervenção, porque seu delírio é movimento de vida. $\mathrm{O}$ analista se mantém na escuta do delírio e, dessa forma, o delírio vai mantendo Rebeca em movimento. Se procura suportar a demanda que me sobrevém.

Considera-se que o conceito de psicose ordinária parece se adequar bem ao caso Rebeca, tendo em vista que engloba os casos de psicoses compensadas, não desencadeadas, mediadas, em terapia, em análise ${ }^{18}$. Esse conceito advém dos últimos estudos lacanianos, que ressalta que as classificações nosográficas escondem o que existe de singular em cada caso. 0 diagnóstico na psicanálise é só uma orientação para o manejo clínico, pois não se pode perder de vista a singularidade do sujeito.

O semblante é o discurso daquilo que não é, porque, na verdade, sua função é encobrir o real, é falar daquilo que parece ser, mas não é. É no real que o psicótico constrói seu discurso.

Em primeira instância, pode-se dizer que a psicose é uma estrutura. Mas o que se quer afirmar quando se coloca essa definição? De uma forma bem simplificada, é possível afirmar que a psicose pode ser diagnosticada a partir da transferência, ou seja, não é a presença dos sintomas que nos faz descrever esse ou aquele sujeito como psicótico.

É provável que se tenha um paciente assintomático, do ponto de vista da psiquiatria clássica e, no entanto, no trabalho com o analista, ficar evidente a sua estrutura. Pode-se dizer que o que o caracteriza como psicótico é seu modus operandi no mundo e no seu entorno.

O Grupo Vida se sustenta em uma tríade social: pacientes, mamãe e papai e, trazendo essa abordagem para o atendimento individual, forma-se uma díade: analista e analisando ${ }^{19}$. Só o atendimento individual não é suficiente, o grupo dá o suporte e a condição de espelhamento que os conforta. Uma boa clínica da psicose sustenta-se na articulação entre atendimento em grupo e individual, mas, ao optar por fazer o atendimento individual, o analista tem que estar ciente de que ele pode ser solicitado a qualquer momento, e avaliar se suporta essa transferência maciça e intensa ${ }^{19}$.

\section{CONCLUSÃo}

A clínica da psicose é um árduo trabalho, mas Rebeca conseguiu se posicionar e se descolar da família. Atualmente, está trabalhando, tem mantido um bom contato social com os demais membros do Grupo Vida e com seus colegas de trabalho. Essa clínica é cativante porque, de alguma forma, o vínculo com os pacientes permanece; é uma análise interminável, que exige coragem e determinação do analista.

No atendimento a Rebeca, o analista se deparou ante seus delírios, mas não os temeu; enfrentou e ela se viu amparada e conseguiu dar um sentido para o vazio. 0 grande mérito de Rebeca foi sua persistência em continuar no processo analítico, lutando incessantemente contra os fantasmas que lhe assolavam.

No Grupo Vida, se observa sua melhora, a paciente consegue se colocar, falar das suas dificuldades, e ouve as dificuldades dos demais. O grupo ocupa o lugar da família; no entanto, é na análise individual que ela encontra o sustentáculo para seguir em frente. A conjunção do par "análise individual e trabalho em grupo" constitui-se um espaço muito produtivo e de saúde.

Este estudo tem como limitação se dirigir a apenas um caso, mas traz ao mesmo tempo, a possibilidade de compreensão que a intervenção analítica na psicose é possível, mesmo que complexa e que requeira outros instrumentais, diferentes da clínica de neuroses. 


\section{REFERÊNCIAS}

1. Lacan J. De uma questão preliminar a todo tratamento possível da psicose. In: Escritos. Rio de Janeiro: Zahar; 1998. p.12-9.

2. Freud S. Sobre a psicoterapia (1904). In: Um caso de histeria, Três ensaios sobre sexualidade e outros trabalhos (1901-1905). Rio de Janeiro: Imago; 1996a. (Edição Standard Brasileira das Obras Psicológicas Completas de Sigmund Freud; 7). p. 159-68.

3. Freud S. Observações psicanalíticas sobre um caso de paranoia relatado em autobiografia ("O caso Schreber"), artigos sobre técnica e outros textos (1911-1913). São Paulo: Companhia das Letras; 2010.

4. Santos TC, Oliveira FLG. Teoria e clínica psicanalítica da psicose em Freud e Lacan. PsicolEstud.[Internet]. 2012 [citado em 09 mar 2021]; 17(1):73-82. Disponível em: https://www.scielo.br/pdf/pe/v17n1/v17n1a08.pdf

5. Freud S. Neurose e psicose. In: 0 ego e o id e outros trabalhos (1923-1925). Rio de Janeiro: Imago; 1996e. (Edição Standard Brasileira das Obras Psicológicas Completas de Sigmund Freud; 19). p. 88-91.

6. Freud S. A perda da realidade na neurose e na psicose. In: 0 ego e o id e outros trabalhos (1923-1925). Rio de Janeiro: Imago; 1996f. (Edição Standard Brasileira das Obras Psicológicas Completas de Sigmund Freud; 19). p. 107-10.

7. Fonseca SO. Rabinovitch S. A foraclusão. Presos do lado de fora.Psychê 2006 [citado em 09 mar 2021]; 10(17):185-6. Disponível em:http://pepsic.bvsalud.org/pdf/psyche/v10n17/v10n17a12.pdf

8. Fulgencio L. A teoria da libido em Freud como uma hipótese especulativa. Ágora [Internet]. 2002 [citado em 09 mar 2021];5(1):101-11. Disponível em: https://www.scielo.br/pdf/agora/v5n1/v5n1a08.pdf

9. Lacan J. O seminário, livro 8: a transferência. Rio de Janeiro: Jorge Zahar; 1992.p. 224

10. Freud S. Notas psicanalíticas sobre um relato autobiográfico de um caso de paranoia (dementia paranoides) (1911). In: 0 caso Schreber, artigos sobre técnica e outros trabalhos (1911-1913). Rio de Janeiro: Imago; 1996d. (Edição Standard Brasileira das Obras Psicológicas Completas de Sigmund Freud; 12). p. ??-??

11. Albino A. Encontros e desencontros na clínica da psicose: uma reflexão psicanalítica. São Paulo: Instituto Langage; 2015. 127p.

12. Miller JA. Introducción al método psicoanalítico. Buenos Aires: Paidós; 2006.

13. Lacan J. O seminário, livro 3: as psicoses (1955-1956). Rio de Janeiro: Zahar; 1985. 369p.

14. Kuperman D. Presença sensível: a experiência da transferência em Freud, Ferenczi e Winnicott. J Psicanál.[Internet]. 2008 [citado em 09 mar 2021]; 41(75):75-96. Disponível em: http://pepsic.bvsalud.org/pdf/jp/v41n75/v41n75a06.pdf

15. Sobrinho JGS. A perspectiva do cuidado na psicanálise do século XXI. LeitFlutuante [Internet].2015 [citado em 09 mar 2021]; 7(2):51-61. Disponível em: https://revistas.pucsp.br/index.php/leituraflutuante/article/view/25901/18575

16. Loureiro LF. A relação com Deus e o sinthoma: a clínica psicanalítica face ao religioso. RevaSEPHallus [Internet]. 2013 [citado em 12 fev 2019]; 8(15):59-68. Disponível em: http://www.isepol.com/asephallus/numero_15/artigo_03.html

17. Nasio JD. Os grandes casos de psicose. Rio de Janeiro: Zahar; 2001. 113p.

18. Tironi AC. A psicose ordinária e os inclassificáveis das categorias lacanianas. Opção Lacan. [Internet]. 2010 [citado em 11 jan 2019]; 1(1):1-11. Disponível em: http://www.opcaolacaniana.com.br/pdf/numero_1/Psicose_ordinaria.pdf

19. Albino A, Barros MTM, Herszkowicz S, Abete M. Análise em grupo com pacientes psicóticos: a experiência do "grupo vida". REFACS [Internet]. 2020 [citado em 09 mar 2021];8(1):137-46. Disponível

em: 
Editora Associada: Divanice Contim

\section{CONTRIBUIÇÕES}

Silvia Herszkowicz contribuiu na concepção, análise e redação. Araceli Albino colaborou na redação e revisão.

\section{Como citar este artigo (Vancouver)}

Herszkowicz S, Albino A. A clínica da psicose: um estudo de caso. REFACS [Internet]. 2021 [citado em inserir dia, mês e ano de acesso]; 9(2):503-13. Disponível em: inserir link de acesso. DOI: inserir link do DOI

\section{Como citar este artigo (ABNT)}

HERSZKOWICZ, S.; ALBINO, A. A clínica da psicose: um estudo de caso. REFACS, Uberaba, MG, v. 9, n. 2, p. 503-13, 2021. DOI: inserir link do DOI. Disponível em: inserir link de acesso. Acesso em: inserir dia, mês e ano de acesso.

\section{Como citar este artigo (APA)}

Herszkowicz S., \& Albino, A. (2021). A clínica da psicose: um estudo de caso. REFACS, 9(2), 503-13. Recuperado em inserir dia, mês e ano de acesso de inserir link de acesso. DOI: inserir link do DOI. 